\title{
Ignacio Ellacuría. Teología, filosofía y crítica de la ideología, de Juan José Tamayo Acosta y José Manuel Romero Cuevas
}

\author{
Ángel Alfonso Centeno \\ Universidad Centroamericana \\ "José Simeón Cañas", UCA
}

Libro escrito a dos manos, Ignacio Ellacuría. Teología, filosofía y crítica de la ideología cumple de sobra su propósito de ser un homenaje a la figura intelectual de Ignacio Ellacuría en el trigésimo aniversario de su asesinato, siendo no sólo testimonio de la inspiración de su figura religiosa y política sino también un diálogo vivo, crítico y fructífero con su obra teórica. Trae a la actualidad los aportes y límites de su método crítico de las ideologías (la historización de los conceptos), resultando de especial relevancia para teólogos, filósofos y especial istas e interesados en la obra de Ellacuría, así como en la teología de la liberación, la filosofía latinoamericana, la teoría crítica, la teoría social, la teoría decolonial, las epistemologías del Sur y los
Derechos humanos, en un contexto como el actual donde el reaccionarismo político toma diversas formas irracionalistas, fundamentalistas, sexistas, homófobas, neocoloniales y antidemocráticas. La primera parte, escrita por Juan José Tamayo, conocido teólogo de la liberación, lleva a cabo la historización de diversos conceptos teológicos, y adelanta además el valor del aporte ellacuriano para una decolonización de la teología en general. La segunda es escrita por el filósofo José Manuel Romero, quien revisa críticamente las premisas metodológicas de la historización -aplicada a una serie de conceptos políticos- y proponiendo al final una reveladora exégesis del pensamiento ellacuriano. 


\section{La transformación de la teología}

Juan José Tamayo, cofundador y actual secretario general de la Asociación de Teólogos y Teólogas Juan XXIII, conoció a Ellacuría desde 1979, en las vísperas de la III Conferencia Episcopal Latinoamericana de Puebla, y desde entonces colaboraron en diversos proyectos debido a la sintonía entre ambos acerca de la manera de hacer y entender la teología. En la primera parte escrita por él, "Método de historización de los conceptos teológicos" (pp. 9-80), Tamayo somete la teología prácticamente en su totalidad a la historización ellacuriana: su punto de partida, su metodología y sus fundamentos, así como conceptos centrales del cristianismo como historia, revelación, salvación, liberación, Dios, Jesús, espiritualidad, fe, Iglesia, Reino de Dios, religiones abrahamánicas, opción por los pobres, profetismo y utopía. La concepción de una inteligencia situada y encargada de la realidad, heredada por Ellacuría de su maestro Xavier Zubiri, determina éticamente el posicionamiento inicial de la teología cristalizándose en la pregunta de para quién y para qué se hace teología (pp. 10-12). Si los conceptos heredados de las varias tradiciones teológicas arrastran su situacionalidad y función política no siempre explícita, entonces es necesario desvelar su historicidad y espacialidad para resituarlos en la actualidad y en el contexto geopo- lítico propio del Tercer Mundo y los países del Sur global.

Según Tamayo, la historización (pp. 13-17) puede llevar a cabo esta tarea y asumir la decolonización de los conceptos teológicos. La historización consiste en la comprobación histórica de la verdad de los conceptos y fundamentos de la teología mediante su remisión crítica a su situación histórica así como a su función política. La historización desenmascara así las pretensiones ideologizadas de validez universal y ahistórica que encubren una clara hegemonía colonial sobre las regiones periféricas del capitalismo global. Con ello Tamayo plantea desde el inicio de su lectura de la historización ellacuriana un diálogo de esta teología con las recientes teorías decoloniales y las epistemologías del Sur -y que Tamayo también aborda en otra obra suya. ${ }^{1}$ La historización señala críticamente que los conceptos teológicos no contemplan su mediación con las condiciones históricas que permitirían efectivamente su realización. Esta mediación histórica se convierte así en el criterio determinante para esta teología frente a los tradicionales principios transcendentales de una teología de corte más idealista.

Importante en este procedimiento es la reelaboración del concepto de historia (pp. 17-21) como concepto 
clave al que se remitirán, uno a uno, los demás conceptos esenciales de la teología, rearmando así una disciplina muy diferente a las teologías más clásicas e idealistas. Estas teologías arrancaban del lógos griego, es decir, de la orientación metafísicooccidental hacia la esencialidad de una naturaleza estática que tenían por efecto diluir la densidad real de la historia en una mera sucesión contingente de hechos. Esta noción idealista de la historia ha condicionado que muchos de los conceptos y problemas teológicos se planteen desde un aparato conceptual que invisibiliza su posible realización en la historia y su lugar en las relaciones coloniales. Por otra parte, Tamayo destaca que esta perspectiva metafísica idealista de la historia tampoco le hace justicia a la experiencia religiosa más propia de las religiones abrahamánicas (el Judaísmo, el Cristianismo y el Islam: pp. 46-48), donde la revelación misma de Dios y la salvación se despliegan históricamente. Por ello destaca Tamayo la apuesta ellacuriana de elaborar un nuevo concepto metafísico de historia ${ }^{2}$ que esté a la altura de la experiencia religiosa del cristianismo. La realidad lejos de ser algo concluido y acabado es dinámica y abierta, lugar de realización de nuevas realidades por las posibilidades creadas, transmitidas y mediadas por la praxis humana.

Con la reelaboración del concepto de historia Tamayo analiza la histo- rización de los diversos conceptos teológicos iniciando con los de salvación y revelación (pp. 21-30). Al contrario de suponer un Dios contemplativo y distante sino más bien solidario y compasivo, la revelación de Dios se efectúa en un lugar muy concreto de sufrimiento y con una intención liberadora respecto al sistema opresor de los sujetos históricos (como en el relato del Éxodo donde Yahvé se revela al pueblo esclavo de Israel para liberarlo de Egipto). La consecuente salvación se lleva a cabo también en la historia y lejos de reducirse a una salvación puramente espiritual 0 individual adquiere un carácter comunitario que contempla los momentos estructurales de la realidad histórica (su dimensión material, económica, política, cultural y moral) así como la propia praxis de los sujetos históricos.

Tamayo expone con sistematicidad la historización de los demás conceptos teológicos, completando el análisis de la transformación historizada de la teología. La opción por los pobres (pp. 30-32) deja de consistir en un espiritualismo abstracto que plantea como modelo el ascetismo y pasa a contemplar el dinamismo dialéctico de su exclusión (hay pobres porque hay ricos). La figura de Jesús (pp. 36-37) no es sólo objeto de una reflexión cristológica acerca de su naturaleza humana y divina, sino que asimila como objeto de reflexión los hechos biográficos 
de su vida que lo llevaron a su asesinato, como un contexto necesario para interpretar en su integridad histórica su mensaje salvífico. La espiritualidad (pp. 37-41) no consiste en la mortificación del cuerpo, sino en la asunción de los momentos materiales de la historia y se manifiesta en una praxis histórico-política de liberación. Iglesia, otro concepto de especial atención por parte de Ellacuría (pp. 42-46), es concebida por una parte como una institución objetivada cuyo riesgo de conformarse a las estructuras de poder del mundo secularizado y la reducción de la salvación como fidelidad deshistorizada a la institución eclesial (eclesiocentrismo) se corrige sobre las bases de una reflexión historizada de su lugar social y geopolítico de cara a su “conversión” al Reino de Dios.

Hay que enfatizar la originalidad con que Tamayo lleva su diálogo con Ellacuría hacia el ámbito muy actual de los estudios decoloniales y de las Epistemologías del Sur. ${ }^{3}$ Así por ejemplo, la historización del lugar de la Iglesia es planteada geopolíticamente en el Tercer Mundo, proponiendo una perspectiva decolonial de esta institución. Tamayo también Llama la atención sobre la colonialidad que rige y deforma ideológicamente el discurso sobre los Derechos Humanos (pp. 49-51) y de la paz (51-55). Cuando trate el concepto de Reino de Dios (pp. 68-76), Tamayo cuestionará la cultura como expresión hegemónica del Norte global sobre las invisibilizadas experiencias de resistencia del Sur epistémico y apuesta por una nueva historización de la cultura desde un Sur epistémico (pp. 72-76). ${ }^{4}$

Especial atención reciben la historización de los conceptos ellacurianos de utopía y profetismo en las dos partes del libro, aunque con diversa valoración por parte de Tamayo (pp. 55-80) y Romero (pp. 178-232). Juega aquí especial importancia el estudio de parte de Ellacuría de la obra del filósofo marxista alemán Ernst Bloch, sobre el que Tamayo también se ha especializado. ${ }^{5}$ Como Ellacuría, Bloch elabora una especie de metafísica de la historia y de la naturaleza que hace justicia al concepto de utopia, hasta entonces controversial dentro del marxismo. Si bien existen utopías que son abstracciones ideologizadas de una imagen de mundo ideal $\sin$ las necesarias mediaciones histórico-materiales para su efectiva realización ("utopías abstractas"), Ellacuría, siguiendo a Bloch, revaloriza el papel de las utopias concretas, esto es, la imagen de una sociedad emancipada que contempla a su vez las condiciones de posibilidad de su realización histórica. En este sentido el concepto de utopía concreta es la versión historizada del concepto de utopía. Constelado con el concepto de utopía concreta está el de profetismo, fundamental en la teología de la liberación, y que evoca la conciencia de una realidad 
alternativa en ruptura con la realidad social vigente. El profeta suscita o evoca una comunidad alternativa basada en la compasión y la justicia en contraste con la sociedad denunciada de su tiempo.Ambos conceptos se articulan en el de Reino de Dios (pp. 68-76), cuya historización bien puede sintetizar la profunda transformación ellacuriana de la teología y hacia el cual queda orientada toda esta disciplina. El Reino de Dios toma en cuenta las condiciones que lo hacen posible junto con el poder efectivo de emancipación para prevenir las abstracciones propias de los discursos ideologizados. Los contenidos que lo definen (Nuevo Ser Humano, Nueva Tierra, Nuevo Cielo) entran en mediación con las condiciones histórico-materiales de su realización efectiva - hasta el punto de que Ellacuría toma en cuenta el tipo de sistema económico más propicio para ellos, el socialismopero guardan al mismo tiempo respecto a la realidad histórica misma una diferencia o distancia de transcendencia teológica. Este punto determinará la distinta perspectiva que ambos autores tienen sobre las utopías.
Efectivamente, si bien por una parte Tamayo cuestiona explícitamente la idea de que hay dos historias (una historia profana y otra sagrada) y enfatiza en cambio en la unidad de la historia donde se lleva a cabo la salvación en toda su riqueza estructural propia, por otra parte, sin embargo, contempla la subordinación de los aspectos estructural-materiales de la realidad histórica ("liberación” inmanente) a la salvación teológica. Con ello remarca Tamayo que Ellacuría evita así la acusación de vaciamiento del contenido transcendente propio del cristianismo (p. 27). Esta insistencia de una transcendencia que no puede reducirse ni agotarse históricamente, ni traducirse completamente en un lenguaje secularizado ${ }^{6}$ es especialmente relevante cuando Tamayo trata la historización del Reino de Dios. Este no puede entenderse tan sólo en los términos de una civilización material sino como apertura de la historia humana al nuevo cielo, al Espíritu y a la presencia de Dios entre los seres humanos, es decir, a algo que excede la realidad histórica:

Una salvación histórica que no traiga consigo la solidaridad humana no es salvación histórica, pero no es tampoco historia de la salvación; una salvación histórica que no abra al hombre hacia lo que en él le transciende no puede ser signo de Dios, pero tampoco puede ser plena salvación de la historia. (Ellacuría, citado en p. 76 - las cursivas son mias.) 
Hay que destacar que Tamayo no deja de insistir a este respecto sobre la profunda fe y mística cristianas de Ellacuría frente a las circunstancias del severo examen eclesial sobre éste y otros teólogos de la liberación por parte de la Congregación para la Doctrina de la $\mathrm{Fe}$ (de la que el cardenal Ratzinger era presidente) en la década de los años 80 del siglo pasado (p. 27). Sin embargo, a pesar de que la tensión entre estos dos momentos (el histórico y el teólogico, la inmanencia y la transcendencia) en los conceptos teológicos historizados enriquece su comprensión teológica abriendo incluso una dirección decolonial, por otro lado planteará un problema complejo de congruencia filosófica tal como observará Romero Cuevas en la segunda parte del libro (v. infra).

\section{La historización radical de la utopía ellacuriana}

La segunda parte del libro, titulada "La historización de los conceptos políticos como crítica de la ideología" (pp. 81-232) escrita por José Manuel Romero Cuevas, tiene como problema vertebral de su estudio la cuestión de las bases o fundamentos normativos de la historización, es decir, los fundamentos que sirven como criterios de valoración o de crítica de los discursos ideologizados. A través de un pormenorizado recorrido de los distintos aspectos filosóficos de la historización ellacuriana (con comparaciones iluminadoras con Hegel, Nietzsche, Marx y la tradición marxista occidental más actual que Romero conoce bastante bien) el estudio de Romero propone dos diferentes e incompatibles modelos de crítica subyacentes a la historización ellacuriana: la primera, el modelo filosófico moral y que se expresa como crítica inmanente un tema que Romero desarrolla en otros libros ${ }^{7}-$; y la segunda, como un modelo teológico que tiene como fundamento normativo el concepto de utopía cristiana. Esta convivencia de ambos modelos en la obra de Ellacuría determinará desde el inicio las dificultades desde las cuales interpretar globalmente su obra en general así como el análisis específicamente filosófico de los supuestos metodológicos de la historización, y que tomarán especial relevancia en el análisis de Romero en los apartados 4 y 5 de su estudio.

En el primer apartado (pp. 89-116), por ejemplo, este problema de interpretación global se presenta cuando Romero considera las motivaciones extrafilosóficas (políticas y teológicas) que caracterizan la obra integral de Ellacuría. Hay que añadir que la tensión propia de motivos tan diversos da pie para problematizar la interpretación que se pueda obtener de su obra en general. Romero apuesta que la orientación que preside las relaciones entre estas disciplinas debe encontrar su 
raíz común en una motivación moral -que más adelante se perfila como una motivación política (p. 232)- y que distingue la autocomprensión filosófica de Ellacuría de la de su maestro, Xavier Zubiri, más motivado por un "interés puramente filosófico" y teorético tradicional. La noción de "lugar que da verdad" (p. 90) expresa muy bien esta reflexión ellacuriana sobre su propia "situación hermenéutica” en términos políticos $-y$ que Romero pone de manifiesto en comparación con la formulación de Horkheimer sobre "teoría crítica" y en especial con los esfuerzos del primer Marcuse de sintetizar fenomenología y marxismo (pp. 108-109)- ${ }^{8}$. Las razones que identifica y desarrolla Romero para esta autocomprensión político-moral pueden sintetizarse en tres razones. En primer lugar, la concepción ellacuriana del objeto de la metafísica intramundana -que viene a ser la realidad históricaotorga a la praxis política un significado metafísico relevante, resultando así el ordo más fundamental para una autorreflexión filosóficamente situada. Romero aprecia en este sentido su notable divergencia respecto a la tradición marxista en general y a la teoría crítica frankfurtiana en particular (p. 96), renuentes a recurrir a las especulaciones metafísicas para situar el sentido de su autorreflexión teórica -apuntando aparte el caso excepcional de Ernst Bloch. En segundo lugar, la praxis humana es concebida no sólo metafísicamente sino también como praxis política que incluye necesariamente un momento opcional. Esta opcionalidad no depende de un tipo de decisión enteramente subjetiva e irracional (decisionismo abstracto, pp. 115-116) sino de la dinámica real, divisiva y conflictiva del capitalismo global cuyos procesos de creación, acumulación, distribución y apropiación de riqueza y cultura generan exclusión de una mayoría (los pobres, el Tercer mundo). En tal sentido, la opción ellacuriana por los pobres y el Tercer mundo como "lugar que da verdad" se inserta en la tradición de rememoración de las luchas y fracasos de los sujetos vencidos y excluidos por la historia. En este punto Romero destaca las limitaciones eurocéntricas de la teoría crítica europea (a excepción del caso de Marcuse) que no toma en cuenta el carácter geopolítico y colonial en la consideración de su propia situación histórica ni en sus parámetros de crítica (pp. 113-115). La tercera razón consiste en que la opción por los pobres tiene un fuerte sentido teológico (de la teología de la liberación), proporcionando también una justificación a su vez de una filosofía de "inspiración cristiana" (pp. 101-107).

En los apartados 2 y 3 Romero lleva a cabo un análisis pormenorizado del método de la historización así como algunas aclaraciones conceptuales necesarias para el mismo. El apartado 2 (pp. 117-130) está dedicado a sintetizar la distin- 
ción ellacuriana entre ideología e ideologización, una distinción propia de Ellacuría y ajena al enfoque marxista. Por ejemplo, Ellacuría se distingue al situar la raíz de la ideología en la estructura libre y opcional de la inteligencia humana y se sirve de la trilogía zubiriana sobre la inteligencia sentiente, ${ }^{9}$ convirtiendo la ideología así en una "necesidad antropológica" (p. 123). Por otra parte, el origen de la ideologización ya no reside en el sujeto -ni en la estructura libre de la intelección humana- sino en el dinamismo dialéctico y real de la sociedades de clases y de la historia de la sociedad de clases (p. 123). Romero precisa que este concepto presenta un paralelismo con el complejo uso que tiene el término de "ideología" en la obra de Marx (pp. 83-85): el primero sentido de "ideología" (que Romero ubica en la Ideología alemana, los Grundrisse y en El capital) como falsa consciencia que invierte la realidad social; mientras que el segundo (que Romero identifica en la Introducción a la Filosofía del derecho de Hegel y en El 18 de Brumario de Luis Bonaparte) conteniendo no sólo un momento de falsedad sino también un momento de verdad, en el sentido de protesta y denuncia de la realidad establecida abriendo un contenido utópico que la transciende. Este último sentido tiene un papel importante en Ellacuría que permite establecer una serie de decisivos paralelismos entre la historización y lo que Romero llama "crítica inmanente" desarro- llada por la corriente hegelianomarxista y la teoría crítica en particular, y que volverá a destacar en el apartado 4.

En el tercer apartado (pp.131-161) Romero sintetiza la noción de historización, así como su aplicación en los ejemplos del propio Ellacuría sobre algunos conceptos políticos: propiedad (pp. 139-141), bien común (pp.141-144) y Derechos humanos (pp. 144-155). Romero sintetiza el método de la historización como el proceso de verificación o negación histórica del contenido normativo-abstracto (el momento de verdad y protesta) propio de los discursos ideologizados en las condiciones materiales de su realización y su apropiación por parte de los excluidos y víctimas ("lugar que da verdad"). La historización permite analizar la función de legitimación propia de las ideologizaciones pero a su vez permite contrastar su propio contenido de verdad en cuanto es un contenido frustrado y negado por las mismas mediaciones históricas. La historización suspende las pretensiones de veracidad fáctica de las ideologías destacando a su vez su contenido utópico que orienta la praxis política hacia la superación de la estructura social vigente. Se puede destacar en esto cómo la historización ellacuriana de los Derechos humanos se compara con y supera la genealogía nietzscheana (pp. 159-161) como una crítica "abstracta" y no mediada históricamente, y en la que también se ha especializado Romero. ${ }^{10}$ Tal vez más 
que un proceso de verificación, la historización puede concebirse como un proceso de falsación o, como Romero explica, como un proceso de crítica dialéctica.

El apartado 4 (pp. 162-178) tiene como objetivo de desvelar e interpretar la historización ellacuriana como un modelo de crítica inmanente e historicista. Para ello, Romero compara los momentos formales del método de la historización -en especial el momento de verdad utópica de las ideologizaciones (en el sentido de anhelo colectivo sedimentado históricamente)- con el modelo dialéctico, historicista e inmanente que caracteriza a la crítica de las ideologías de la corriente hegeliano-marxista en autores clásicos y actuales: Ernst Bloch, Walter Benjamin, Theodor Adorno, Fredric Jameson, Susan Buck-Morss, Terry Eagleton, Slavoj Žižek, Hartmut Rosa y Rahel Jaeggi. Bajo esta perspectiva el modelo ellacuriano se revela como una propuesta interesante y actual, "una original versión de esta corriente" (p. 164). De especial interés en este punto es la propuesta de Romero de buscar la génesis de este modelo de crítica inmanente en una fuente no marxista como es en el concepto zubiriano de verdad moral ${ }^{11}$ (pp. 165-173) y que es a su vez aprovechado para radicalizar el modelo ellacuriano de crítica más allá del propio Ellacuría (pp. 170-173): mientras la historización ellacuriana critica las estructuras sociales vigentes a la luz de sus inmanentes ideales normativos, la dirección a la que apunta Romero es la de superar los ideales normativos inmanentes a la luz de las nuevas posibilidades históricas que dormitan en las actuales estructuras materiales de la sociedad -posibilidades que son impedidas tan sólo por la actual configuración de las relaciones sociales y económicas en beneficio de unos pocos. "Esta idea... puede llegar a enriquecer la concepción de historización en una dirección dialéctica más radical que lo que Ellacuría llegó a tematizar expresamente en sus escritos." pp. 172-173).

Escrito aún con mayor espíritu de polémica, el último apartado (pp. 178-226) retoma el problema vertebral del estudio y plantea una crítica decisiva de Ellacuría, referida a la cuestión del fundamento normativo de la historización, planteando además una propuesta alternativa de lectura y apropiación de la misma. Aun cuando la exégesis desarrollada por Romero muestra que el planteamiento de la historización (apartado 4) ofrece los suficientes elementos como para entenderlo en términos de una crítica inmanente (es decir, para afirmar la historicidad e inmanencia de sus fundamentos normativos), es el propio Ellacuría quien interpreta y presenta los fundamentos normativos de la historización como propios de (y compatibles con) una utopía cristiana (pp. 180ss.) en el 
sentido de la realización profética del Reino de Dios en la historia, es decir, bajo el modelo teológico de crítica. De hecho, Ellacuría rehabilita la posibilidad de una filosofía cristiana, pues su fundamento normativo y su orientación emancipadora es "fundamentalmente cristiana" (p. 185) en la línea de la teología de la liberación. Como Tamayo había establecido en su análisis, el Reino de Dios -que viene a dar todos los contenidos de esta utopía cristiana- se historiza en la medida en está mediada con las condiciones histórico-materiales de su realización; sin embargo Tamayo y Romero destacan a este propósito el momento de transcendencia irreductible a las configuraciones vigentes o posibles de la realidad histórica. Este momento de transcendencia irreductible - ¿absoluta?- de la utopía cristiana, que funge como fundamento normativo de la historización, se mantiene a su vez como tal fuera del alcance de la mediación histórica de realización efectiva, quedando así más bien como un caso límite que nunca llega a realizarse: es decir, como una "meta asintótica" de aproximación infinita análoga a las ideas regulativas kantianas de la paz perpetua o de la coincidencia entre virtud (deber racional) y felicidad personal (pp. 181, n. 302). El problema de la utopía cristiana que Romero plantea es que su naturaleza teológico-religiosa (o su traducción a modo de idea regulativa kantiana de aproximación asintótica) supone una transcendencia absoluta que no se diluye, agota ni entra en mediación con las condiciones de posibilidad históricas de su efectiva realización. Los dos modelos (el modelo de crítica inmanente y el modelo teológico) que Romero identifica en la historización ellacuriana se muestran en este apartado como incompatibles. Planteado el fundamento normativo de la historización en términos teológicos y análogamente kantianos, ¿hasta qué punto vuelve a asomarse aquí de nuevo la posibilidad de un fundamento o principio transmundano e incondicional? (p. 186).

Romero desarrolla su crítica a esta idea ellacuriana de utopía cristiana mostrando que sigue siendo una utopia abstracta (p. 207), retomando la distinción de Bloch entre utopía abstracta y concreta, donde la primera no está mediada con la realidad histórica mientras que la segunda sí. Si bien Ellacuría plantea su utopía cristiana como utopía concreta, debidamente mediada e historizada, las observaciones críticas de Tamayo y Romero constatan un "resto de transcendencia" irreductible a la mediación histórica que no sólo se resuelve, sino que más bien se agudiza mediante su formulación en términos de meta infinita a la que nunca es posible llegar fácticamente ni puede corresponderle algo fácticamente. El problema de esta utopía, en suma, es que deja algo fuera de toda mediación o historización críticas. El recurso a una instancia de este tipo transtorna y desfigura el potencial 
original de la historización como un modo de filosofar congruentemente inmanente y radicalmente historicista, dado que la instancia de transcendencia teológica opera a modo de un ex machina innecesario y ajeno a la congruencia argumentativa de Ellacuría que llega incluso a falsear de nuevo su momento de verdad política como utopía abstracta e idea regulativa kantiana. Mientras Tamayo destacó cómo este recurso teológico y transcendente se pone en juego en un planteamiento de ruptura frente a una tradición teológica de corte idealista, ahistórica y espiritualista, Romero se pregunta a qué puede deberse que Ellacuría echara mano de este recurso en un planteamiento filosófico-político (p. 219). A pesar de que confirma la congruencia moral de la vida política e intelectual de Ellacuría, Romero plantea el problema no como una cuestión de coherencia vital sino como una cuestión de incoherencia formal (p. 219) en la historización. La historización no es capaz de historizar completamente sus propios supuestos normativos: una utopía cristiana con un resto irreductible de transcendencia queda fuera del alcance de la propia historización. La crítica de Romero no reside tanto en el carácter religioso, extra-filosófico que exigiría de entrada la asunción de los contenidos concretos del credo cristiano por parte del intelectual (aunque también plantea esta objeción en la p. 214), sino en su carácter abstracto en sentido hegeliano, es decir, no-mediado ni mediable con las condiciones históricas - debido al resto siempre pendiente de transcendencia- que lo convierten en un ideal regulativo de aproximación infinita. La historización historiza todo menos sus propios fundamentos normativos que siguen conservando un carácter transmundano (iy podríamos añadir que hasta extra-argumentativo!)- y en tal sentido no es congruentemente radical consigo misma, pues conserva una instancia de validez suprahistórica.

La propuesta de Romero se puede resumir en "una lectura de Ellacuría a partir de sus textos filosóficos poniendo entre paréntesis su teología" (p. 229). La propuesta consiste, pues, en una lectura y apropiación de la crítica ellacuriana de las ideologías de manera consecuentemente historicista $e$ inmanente, es decir, dispuesta a historizar incluso los fundamentos normativos de los que depende como crítica racional misma y situarlos dentro de la propia génesis histórica y en la tradición propia de las luchas y memorias de los oprimidos, sin necesidad de recurrir a instancias transcendentes ni teológicas. En la historización ellacuriana habría, según como Romero se propuso en el apartado 4, suficientes elementos para prescindir del recurso de una transcendencia teológica o del recurso análogo a una idea regulativa y contrafáctica. Central en esta propuesta de apro- 
piación de Romero es el concepto de transcendencia intrahistórica ( $\mathrm{pp}$. 221-226), en el sentido de una transcendencia que no deje un poso o resto irreductible de transcendencia extramundana sino que sólo se refiera al "transcendimiento" (dentro de la historia) de las relaciones sociales vigentes en la medida en que estas frustran o niegan la realización de los contenidos normativos de verdad de los discursos ideologizados o posibiliten incluso otros más justos. Esta noción de transcendencia intrahistórica funciona pues como proyecto político enteramente mediado, pues cuenta de entrada con las condiciones históricas actuales de su realización. A tal punto que quizá podemos adivinar aquí que Romero parece prescindir incluso del concepto mismo de utopía concreta de Bloch y Ellacuría para evitar resquicios sospechosos de transcendencia extrahistórica y pareciera sugerir más bien el planteamiento de Marcuse de un "final de las utopías", quien en vez de utopías apuesta por proyectos políticos radicales pero enteramente realizables y sin restos de transcendencia extrahistórica (pp. 196-197).

Hay que destacar que la exégesis sistemática de Romero cubre tanto una interpretación global de la obra ellacuriana (filosófica, política, teológica) como un análisis pormenorizado de la congruencia filosófica de la historización con sus propios supuestos normativos. Para finalizar esta reseña, plantearemos una serie de observaciones estrechamente relacionadas entre sí acerca de estos dos aspectos de la exégesis de Romero.

En primer lugar podemos observar el carácter extrafilosófico o extraargumentativo de los contenidos particulares del credo cristiano (en cuanto contenidos de una revelación religiosa) y que no impide jugar argumentativamente el rol de fundamento normativo. Romero objeta la autoridad de dichos contenidos religioso-particulares (p. 214) que el crítico de las ideologías tendría que adoptar para ejercer su crítica de la sociedad establecida -efectivamente la experiencia histórica de los proyectos políticos de emancipación, especialmente de Europa (se volverá sobre este punto más adelante), no precisan contar con este tipo de fundamento normativo religioso ni tampoco de su inspiración religiosa motivadora. Romero no insiste mucho más en este punto, pues no es lo extrafilosófico el verdadero quid de su análisis, así como tampoco su secularización satisfactoria en términos historicistas - algo llevado a cabo por Bloch en sus obras (pp. 210-211)-; pues los motivos extrafilosóficos como la opción política del "lugar que da verdad" determinaban ya de entrada una motivación extrateorética de su actividad filosófica a diferencia de la autocomprensión filosófica de su maestro, Zubiri. El punto en cuestión es el carácter 
extrahistórico y abstracto de la utopía cristiana como tal, de modo que la utopía cristiana no termina de entrar en mediación con el dinamismo de capacitación-posibilitación que caracteriza la realidad histórica. En tal sentido, el motivo político del "lugar que da verdad" sí cuenta con el requisito filosófico de ser intrahistórico e inmanente sino que además es propiamente racional, en el sentido de que también forma parte del juego de la argumentación propia de una filosofía reflexivamente situada en la historia -es decir, es un argumento racional en sentido historicista y de ninguna manera una "decisión" abstracta o arbitraria (pp. $115-116$ y 224). De hecho muchos de los conceptos de la teología de la liberación pueden entrar a formar parte de este juego de la argumentación historicista en la medida en que son historizados -como lo muestra efectivamente Tamayo respecto a la historización de la teología-, pero encuentran su límite de resistencia cuando se considera su irreductible transcendencia. En este sentido, en la exégesis de Romero, el carácter extra-argumentativo de la verdad revelada de la utopía cristiana pasa a segundo plano detrás de la problematización de su carácter abstracto y extrahistórico.

Ahora bien, a partir de un planteamiento consecuentemente histórico-inmanente (y no sólo a partir de la particular experiencia europea) podríamos sugerir de que ambos aspectos de la utopía cristiana (su carácter abstracto no mediado como su carácter extra-argumentativo de contenido religioso particular) parecen tener un asidero común. En un excurso dedicado a la crítica de Hegel a los ideales morales, Romero explica la aplicación de la perspectiva hegeliana a la crítica de las utopías abstractas y concluye, entre otras cosas, en que éstas "son más bien fruto de la ocurrencia o proyección de un deseo puramente particular y arbitrario" (p. 188). De manera semejante podríamos plantear como complementación a la crítica de Romero que también el carácter abstracto de la utopía ellacuriana se encuentra estrechamente vinculado a su carácter arbitrario de religión particular ("abiertamente no universalizable", p. 214) de manera que dicha utopía sólo puede jugar su papel de criterio abstracto jugando al mismo tiempo el papel extraargumentativo de un "deseo particular y arbitrario". En otras palabras, desde una perspectiva consecuentemente inmanente e historicista, el carácter abstracto y el carácter arbitrario (extra-argumentativo y particular) de la utopía cristiana se remiten necesariamente entre sí.

La mutua extrañeza entre lo religioso y lo político es algo que plantea Romero no sólo en su análisis filosófico de la historización ellacuriana ("leer a Ellacuría poniendo entre paréntesis la teología", p. 229), sino también en su forma presupuesta 
de entender las luchas políticas de "quienes comparten un posicionamiento político-moral [es decir, no necesariamente religioso] que pretende ser emancipador (al que podemos adscribir la posición del propio Ellacuría), sustentado en razones morales y políticas que aspira a devenir universalizable" ( $p$. 214 -los corchetes son míos).

Una segunda observación obliga a revisar este planteamiento, obligando a su vez a revisar la interpretación global de la obra integral de Ellacuría así como la compleja tensión de los motivos teoréticos y extra-teoréticos que la configuran. En el contexto histórico de América Latina en los años 70 y 80 del pasado siglo, y de El Salvador en particular durante esas décadas, el cristianismo y la teología en su versión liberadora no sólo contaron con alguna influencia en la jerarquía eclesial (al menos temporalmente), sino que llegaron a ejercer una función contrahegemónica entre los catequistas (que llegaron a ejercer un rol análogo a la intelectualidad orgánica gramsciana) y entre el movimiento de las comunidades eclesiales de base (que llegaron a alimentar un movimiento social y político a nivel continental nada despreciable y que en el caso de $\mathrm{El}$ Salvador, alimentaron masivamente el movimiento político de centroizquierda). En suma: la religión tenía suficiente fuerza histórica para ser considerada en este sentido como un factor político e inmanente en la dinámica conflictiva y colonial de las relaciones del sistema-mundo capitalista. Bajo esta luz podríamos reconsiderar que la valoración positiva de Ellacuría sobre la fuerza motivadora de la utopía cristiana tuviese también motivos políticos reales, hasta el punto de preguntarnos por la posibilidad de una valoración política positiva (es decir, en términos histórico-inmanentes y no como una valoración meramente religioso-particular) más allá de un mero "deseo particular y arbitrario". ${ }^{12}$ Como critica Maldonado-Torres a Žižek, las maneras en que opera aquello que llamamos religión nunca se efectúan en abstracto, en el vacío de ningún contexto de las relaciones coloniales. ${ }^{13}$ Esto no quiere decir que la crítica filosófica de Romero al recurso teológico, extrateorético y extrafilosófico de la utopía en la historización deba rechazarse. Como análisis crítico y filosófico de la congruencia de la historización es válida. Lo que sugerimos más bien es que es posible poner sobre la mesa de análisis una consideración del contexto histórico en términos de periferia colonial para una interpretación global de las motivaciones extrateóricas de la obra integral de Ellacuría así como la discusión de su actual vigencia en los mismos términos.

Todo lo anterior nos lleva a plantear una tercera observación. En vista de que la religión -como en el caso 
particular de la teología de la liberación- pudo jugar un papel contrahegemónico y de fuerza política real en Latinoamérica, habría que preguntarse qué "tradiciones políticas" son las que deben iluminar e interpretar los contenidos normativos intrahistóricos. Según Romero, estas tradiciones políticas tienen la función de interpretar desde el sostén específico de la particular historia o tradición de determinados movimientos o sujetos históricos los contenidos normativos vigentes, de manera que desarrollan, diversifican y concretan desde su experiencia de luchas, conquistas y fracasos el para nada homogéneo y monolítico sentido emancipatorio de la Ilustración moderna. Romero menciona algunas de estas tradiciones políticas ( $p$. 224): el socialismo, el republicanismo, el anarquismo, el feminismo, el progresismo, etc. que tienen todas ellas su origen en el seno de sociedades modernas occidentales y están en buena medida depuradas de todo contenido religioso específico. Estas tradiciones estuvieron y están presentes no sólo en Latinoamérica sino también en el resto de la periferia global, e incluso en el caso de Ellacuría, éste interpreta y modula el sentido crítico de la emancipación desde la perspectiva de la tradición socialista -algo que también había notado Tamayo (pp. 76-77). Sin embargo, el cristianismo, como mencionamos, ha jugado también un papel contrahegemónico subs- tancial en la periferia colonial, lo que abre la posibilidad de pensar otras tradiciones políticas de otros sujetos políticos ${ }^{14}$ para interpretar los contenidos normativos inmanentes a las sociedades vigentes. Aunque estos puntos nos pueden llevar efectivamente más allá de Ellacuría (sería una discusión aparte), la cuestión que podemos plantear aquí a la exégesis de Romero es sobre la previa elección de determinadas tradiciones políticas emancipatorias europeas para interpretar y, finalmente, asimilar la obra integral del pensamiento de Ellacuría. Por una parte, esta elección se debe a que guarda congruencia no sólo formal sino también política con la a su vez congruente radicalización historicista de la historización: una tradición política secularizada y universalista guarda mejor coherencia con un fundamento normativo inmanentemente histórico que con uno de carácter religioso y particular ("abiertamente no universalizable", p. 214). Pero el rol de la teología de la liberación como fuerza política real dentro de unas precisas relaciones coloniales no sólo invita a pensar la interpretación global de la obra integral de Ellacuría como dijimos, sino que también deja abierta (o cerrada) la posibilidad de su apropiación por parte de otras tradiciones políticas emancipatorias desde una perspectiva decolonial o del Sur epistémico, como Tamayo bien apunta en la primera parte del libro. 


\section{Referencias bibliográficas}

- Tamayo Acosta, J.J. y José Manuel Romero Cuevas ( 2019). Ignacio Ellacuría. Teología, filosofía y crítica de la ideología. Barcelona: Anthropos.

\section{Notas}

1 Teologias del Sur. El giro descolonizador, Trotta, 2017.

2 Ignacio Ellacuria, Filosofía de la realidad histórica, San Salvador: UCA Editores, 1990/Madrid: Trotta,1991.

3 Tamayo, Teologias del Sur. El giro descolonizador, op. cit.

4 Nociones de Norte y Sur global así como de Norte y Sur epistémicos son factura de Boaventura de Sousa Santos (cf. Santos, Boaventura/Meneses, Paula (eds.), Epistemologias del Sur. Perspectivas, Madrid: AkaL, 2016).

5 Tamayo,JJ., Religión, razón y esperanza. El pensamiento de Ernst Bloch, Tirant lo Blanch, 2015.

6 Un proyecto llevado a cabo por Ernst Bloch y que Tamayo señala es la razón de su incompleta asimilación en la teología por parte de Jürgen Moltmann: p. 210, nota 393.

7 Hacia una hermenéutica dialéctica, Síntesis, 2005; Crítica e historicidad. Ensayos para pensar las bases de una teoria crítica, Herder, 2010; y El lugar de la crítica. Teoría critica, hermenéutica y el problema de la transcendencia intrahistórica, Biblioteca Nueva, 2016.

8 Marcuse, H., Sobre Marxy Heidegger. Escritos filosóficos (1932-1933), Biblioteca Nueva/Minerva, 2016 (J.M. Romero Cuevas, ed.).

9 Zubiri, X., Inteligencia sentiente (tres volúmenes), Alianza EditoriaL, 1980-1983.

10 Romero Cuevas, ¿Con Nietzsche contra Nietzsche? Ensayos de critica inmanente, Solus Locus, 2016.

11 Xavier Zubiri, Sobre el hombre, Alianza/Fundación Xavier Zubiri, 1986, editado por Ellacuría. En la actualidad la Fundación Xavier Zubiri cuenta con una nueva edición distinta a la de Ellacuría.

12 Naturalmente el contexto ha cambiado hoy día hasta el punto de que puede ponerse incluso sobre la mesa de discusión la actual vigencia de una valoración positiva de la religión por parte de Ellacuría en términos inmanentemente políticos, dado que el contexto religioso en el continente y la orientación política de las comunidades cristianas han cambiado hacia una dirección sensiblemente más conservadora (aunque no siempre) con el creciente impacto del evangelismo pentecostal.

13 Maldonado-Torres, N., "La topología del ser y la geopolítica del saber", en Santos/Meneses (eds.), Epistemologias del Sur. Perspectivas, op. cit., p. 359.

14 Como por ejemplo, comunidades indígenas o afrodescendientes, sean o no cristianas, más los feminismos o transfeminismos cruzados dentro de ellas, cuyos intereses y prácticas coinciden (o no) con los de las tradiciones políticas emancipatorias ilustradas occidentales. Cf. Santos/Meneses (eds.), Epistemologias del Sur. Perspectivas, op. cit. 


\section{Normas de publicación en Realidad}

Realidad publica ensayos, notas y reseñas en idioma español relacionados con las diversas disciplinas de las ciencias sociales y las humanidades. Los artículos publicados por Realidad podrán ser difundidos posteriormente en cualquier medio, siempre y cuando se indiquen los datos de publicación original.

La publicación de originales se rige por medio de las siguientes normas:

\section{Presentación de artículos, notas y reseñas}

Los trabajos se remitirán en formato Word como documentos adjuntos de correo electrónico a la siguiente dirección: realidad.director@uca.edu.sv

O a la dirección postal:

Ricardo Roque Baldovinos

Director de Realidad, Revista de Ciencias Sociales y Humanidades Apartado Postal (01) 168

San Salvador

El Salvador

\section{Presentación de ensayos}

a. El ensayo deberá ser original, inédito y de alta calidad académica.

b. El ensayo deberá ir precedido de dos resúmenes de entre 100 y 150 palabras cada uno: el primero, se escribirá en español y el segundo en inglés. También deberá llevar al menos 6 palabras claves en esos dos idiomas.

c. El nombre del autor o autores irá consignado después del título del mismo. A continuación, se incluirá el nombre de la universidad o la institución de afiliación.

d. Las palabras en una lengua diferente a la de la redacción del texto aparecerán en cursiva; asimismo se empleará este tipo de letra para resaltar alguna palabra clave, y cuando esto suceda en un fragmento textual en cursiva, se procederá de modo contrario, i.e., destacar la palabra clave en caracteres normales.

e. Las figuras, ilustraciones y tablas deberán ir numeradas con cifras arábigas y con un pie indicando su contenido; se incluirán preferentemente en el documento de Word. De no ser posible, se adjuntarán en archivos separados. 
f. La extensión mínima para los ensayos es de 35,000 caracteres y la máxima de 75,000. Para los notas y las reseñas la extensión máxima es de 25,000 caracteres. En el conteo de caracteres se incluyen notan y se excluyen espacios en blanco.

\subsection{Tipo y tamaño de letra}

Los originales se presentarán con justificación completa en letra Arial 11 puntos para el texto, la bibliografía, las citas y los resúmenes o abstracts. La letra Arial 10 puntos se requiere para las notas, números sobrescritos, tablas $y$ figuras.

\section{a) Apartados y subapartados}

Los títulos de los apartados se presentarán en negrita, numerados con cifras arábigas, y separados por dos líneas del texto anterior y por una línea del texto siguiente. En cuanto a los títulos de los subapartados, se anotarán en negritas y serán nuevamente numerados (v. gr., 1.1., 1.2., 1.3.), debiendo separarse por una línea tanto del texto que antecede como del texto subsiguiente. Los niveles siguientes, que deberán evitarse en lo posible, serán numerados igualmente con cifras arábigas y se escribirán en texto común (v. gr., 1.1.1., 1.1.2.; 1.1.1.1., 1.1.1.2.).

\section{b) Referencias bibliográficas}

Los autores enviarán sus colaboraciones en el sistemas en referencias bibliográficas APA.

\section{Presentación de comentarios y recensiones bibliográficas}

Tanto los comentarios como las recensiones se regirán por los mismos requisitos en cuanto al tipo y el tamaño de letra. La extensión mínima de los comentarios es de 5,000 caracteres y la máxima, de 25,000. Los comentarios no requieren resumen. Las recensiones de libros irán encabezadas por la ficha técnica del libro (Autor o autores, Título del libro, Ciudad, Año, número de páginas. Número de ISBN). Tendrán un máximo de 12,000 caracteres. Al final de la recensión, se incluirá el nombre del autor o autora de la misma y el nombre de la universidad o institución de procedencia.

\section{Criterios de publicación}

Todos los trabajos sometidos serán arbitrados por pares en los sistemas visto, ciego o doble ciego. No se entablará correspondencia por trabajos no solicitados. 